Comparative Philosophy Volume 5, No. 1 (2014): 55-78

Open Access / ISSN 2151-6014

www.comparativephilosophy.org

\title{
LIGHT AND AFFECTS FROM A COMPARATIVE POINT OF VIEW
}

\author{
KYLE TAKAKI
}

\begin{abstract}
Light metaphors occurring in Chinese philosophy and Stoicism are of special interest for the unique ways they channel potentialities of the self. In this paper I apply ideas from cognitive linguistics to examine selected structural features of these metaphors. I also build on these ideas by presenting a framework regarding affects to assist in disclosing what is at stake for differing Chinese and Stoic technologies of the self. The paper adopts a highlevel perspective to see these broad philosophical implications, interleaving discussions of Chinese philosophy (mainly views associated with Daoism), Stoicism (bringing into relief important differences from these views), and contemporary research on socially constructed affects. This "triadic" comparative approach aims to shed new light on some root assumptions built into the projects of self-cultivation that are at the core of Chinese and Stoic worldviews.
\end{abstract}

Keywords: emptying-out, harmony, image schema, metaphor, threefold interaction, constructivism

\section{INTRODUCTION}

Light metaphors occurring in various philosophical and religious traditions are often tied to forms of self-cultivation. Light metaphors occurring in Chinese philosophy and Stoicism in particular are of special interest for the unique ways they channel potentialities of the self. In this paper I apply ideas from cognitive linguistics, primarily from the work of George Lakoff and Mark Johnson, to examine selected structural features of these metaphors. Since these metaphors occur in a wider social and normative context, I similarly step back and present a framework regarding affects to assist in disclosing what is at stake for differing Chinese and Stoic technologies of the self. The paper adopts a high-level perspective to see these broad philosophical implications, interleaving discussions of Chinese philosophy (mainly views associated with Daoism), Stoicism (bringing into relief important differences

TAKAKI, KYLE: Independent Scholar, USA. Email: ktakaki@ hawaii.edu 
from these views), and contemporary research on socially constructed affects. This "triadic" comparative approach aims to shed new light on some root assumptions built into the projects of self-cultivation that are at the core of Chinese and Stoic worldviews.

\section{IMAGE SCHEMAS AND METAPHOR}

One of the most important claims from the work being done on metaphor in cognitive linguistics is that metaphor is not just a linguistic figure; it is primordially an embodied mode by which we think. I think this insight resonates with Chinese philosophy, given Chinese philosophy's widespread use of metaphor and the importance placed on (embodied) contextual particularities. This section covers selected ideas from cognitive linguistics that will be used to excavate features of metaphors pertaining to xin ("heart-mind") and light.

To begin, metaphor and embodiment are linked through what is termed an "image schema," which Johnson characterizes as "a recurrent pattern, shape, and regularity in, or of, those ongoing ordering activities.... [It consists of a] small number of parts and relations, by virtue of which it can structure indefinitely many perceptions, [concrete] images, and events" (Johnson 1987, 29). It is crucial to note that image schemas are embodied at a preconceptual level, and provide structure to many of our higher-order modes of cognition, including linguistic expressions of metaphor, simile, and so forth. Image schemas have two important features: they are nonpropositional (in the sense of being rooted in perceptual-sensorimotor processes), and they have a figurative embodied character. As Johnson writes:

Because of the limitations of our propositional modes of representation, we have a hard time trying to express the full meaning of our experiences. To cite a simple example, my present sense of being balanced upright in space at this moment is surely a nonpropositional awareness that I have, even though all my efforts to communicate its reality to you will involve propositional structures (Johnson 1987, 4).

In addition to being nonpropositional and figurative, image schemas are experiential gestalts/patterns rooted in perceptual-sensorimotor processes that are broadly coincident with Deweyan habits (Lakoff and Johnson 1999, 97). Thus while image schemas are historically indebted to Kantian schemata, they are actually a part of a research program that empirically investigates these non-transcendental, transactive habit-patterns (Lakoff and Johnson 1999, 80-81; see also Hampe 2005).

The figurative embodied character of image schemas is closely tied to the formation of metaphor, whether in its narrow linguistic form or more widely as a cognitive structure. In general, image schemas dynamically support and enable a number of important embodied structures in addition to metaphor, such as metonymy, radial categories, and so on (Lakoff 1987). Since in this paper I focus on metaphor, image schemas make possible what Johnson calls "metaphorical projections," which 
extend an image "schema from the physical to the nonphysical" (Johnson 1987, 34). ${ }^{1}$ To illustrate, the expression "tell me your story again, but leave out the minor details" projects the physically based CONTAINER image schema, which arises from embodied processes such as using a cup, or being a physically bounded organism with "inner stuff," to the telling of a story (Johnson 1987, 34). ${ }^{2}$ The CONTAINER schema allows for conceptualizing the telling of a story, which is strictly speaking a nonphysical conceptual entity, in terms of this container. The view of metaphor that Lakoff and Johnson argue for treats "metaphor as a matter of projections and mappings across different domains in the actual structuring of our experience (and not just in our reflection on already existing structures)" (Johnson 1987, 74).

These mappings can take on various forms; for example, Lakoff and Johnson spend a fair amount of time discussing what they call "conventional metaphors," under which fall "orientational," "ontological," and "structural" metaphors. Very briefly, structural metaphors are metaphors that structure one concept in terms of another (usually through highlighting); orientational metaphors organize "a whole system of concepts with respect to one another" (Lakoff and Johnson 1980, 14); and ontological metaphors provide "ways of viewing events, actions, emotions, ideas, etc., as entities and substances" (Lakoff and Johnson 1980, 25). Lakoff and Johnson argue more broadly that new concepts are often grounded in conventional metaphors. Thus one virtue of their view is that it accounts for not only how dead metaphors work - entrenched metaphors that are sometimes mistaken for literal or propositional modes of thought - but also how new metaphors are formed from dead metaphors. To reemphasize, metaphor, as an experiential and embodied structure, is not merely a linguistic figure; this is only one of its manifestations. Thus in general, "the essence of metaphor is understanding and experiencing one kind of thing in terms of another" (Lakoff and Johnson 1980, 5). For Lakoff and Johnson, "human thought processes are largely metaphorical" (Lakoff and Johnson 1980, 6); the main function that metaphor serves is to structure our ideas by the mapping of select information from one domain to another. ${ }^{3}$

\footnotetext{
${ }^{1}$ For Lakoff and Johnson, nonpropositional image schemas structure a significant region of our cognition that is classified as metaphorical. Metaphor, as an embodied cognitive structure, is a mapping from a source domain to a target domain, where the two domains are often quite different yet share certain salient features brought to the fore by the mapping; it is the systematic nature of the embodied mapping that constitutes metaphor as a cognitive structure. Thus for Lakoff and Johnson's research program, it is beside the point whether metaphor is propositional, picks out salient features from differing propositional domains, or is primarily a communicative tool. For such conceptions miss the underlying embodied aspect of metaphor that enables kinds of thinking, communicating, experiencing, and so forth.

${ }^{2}$ By convention, image schemas and metaphors are signified by capitalization.

${ }^{3}$ Lakoff and Johnson spend a fair amount of time covering various theories of metaphor and how their novel account is superior in marshalling empirical evidence from cognitive science. I think separate and convergent support for their views can be found in Antonio Damasio's work (Damasio 1994, 1999, 2003, 2011). Damasio similarly marshals neurobiological evidence in support of his view that our understanding of our external world and ourselves originates out of projected mappings of the body's interior (compare Gibbs 2005).
} 
To use orientational metaphors as an illustration, an example of which will appear in section four, such metaphors do as the name suggests: they orient concepts. Lakoff and Johnson claim that most of our orientational metaphors are spatial in nature, since "we have bodies of the sort we have and that they function as they do in our physical environment" (Lakoff and Johnson 1980, 14). Even stronger, many of our most fundamental concepts are spatial in nature and are organized through spatial metaphors (Lakoff and Johnson 1980, 17). Each orientational metaphor has its own internal coherence that allows new experiences to conform to its structure. There is also an external systematicity among spatialization metaphors, thus delineating a coherence among metaphors (Lakoff and Johnson 1980, 18). For example, the metaphor "GOOD IS UP gives an UP orientation to general well-being [which indicates internal coherence], and this orientation is [also "externally"] coherent with special cases [of other metaphors] like HAPPY IS UP, HEALTH IS UP, ALIVE IS UP, CONTROL IS UP" (Lakoff and Johnson 1980, 18). Orientational metaphors, and metaphors in general, also crucially interact with social and cultural factors that differ from culture to culture, although certain basic physical metaphors are found throughout all cultures. However, as Lakoff and Johnson note, it is "hard to distinguish the physical from the cultural basis of a metaphor, since the choice of one physical basis from among many possible ones has to do with cultural coherence" (Lakoff and Johnson 1980, 19).

Such coherence (internal, external, and cultural) intimately relates to the generation of new metaphors. Structural metaphors in particular are a fruitful source for new metaphors, since the general categories they establish "allow us to do much more than just orient concepts, refer to them, quantify them, etc., as we do with simple orientational and ontological metaphors; they allow us, in addition, to use one highly structured and clearly delineated concept to structure another" (Lakoff and Johnson 1980, 61). Although orientational and ontological metaphors also can be extended so that new, emergent metaphors and concepts can arise, structural metaphors have much more traction in the formation of new concepts. It is important to note that all three types of metaphor share the same grounding: the systematic correlations in our experience (which fundamentally are based in our bodily interactions) (Lakoff and Johnson 1980, 61). These systematic correlations form image schemas that in turn form categories and subcategories. Subcategorization, for example, occurs when an activity is of the same kind of activity that is involved in the formation of the relevant category, and also shares "enough of the same structural features" (Lakoff and Johnson 1980, 84). Metaphors, by contrast, show a "difference in kind of activity, and partial structuring" (Lakoff and Johnson 1980, 84). The point is that both metaphor and subcategorization have the same grounding, and are "endpoints on a continuum" (Lakoff and Johnson 1980, 85). New concept formation is thus like a plastic material in that metaphor stretches the surface outwards and into different forms, while subcategorization tends to contract the surface back into its "natural" resting shape. New concept formation occurs along this continuum, where metaphor and subcategorization interact. This continuum is directed from subcategorization to metaphor (from resting shape to stretched surface, as it were), 
and is made possible by the formation of categories, or experiential gestalts, which are "multidimensional structural wholes. Structuring our experience in terms of such multidimensional gestalts is what makes our experience coherent" (Lakoff and Johnson 1980, 81). Thus metaphorical coherence is based on the coherence that arises from the formation of categories, which in turn emerges from bodily, physical, and cultural interactions.

There are several important points about metaphorical coherence. The first is that metaphors have "entailments" (as Lakoff and Johnson call them), which are the various senses in which a metaphor can be unpacked. For example, in the metaphor "an argument is a journey," since a journey defines a path, an entailment would be "an argument defines a path" (Lakoff and Johnson 1980, 91; see chapter 16 for more). Entailments "play an essential role in linking all of the instances of a single metaphorical structuring of a concept" (Lakoff and Johnson 1980, 96). Secondly, metaphorical entailments "play an essential role in linking two different metaphorical structurings of a single concept" (Lakoff and Johnson 1980, 96). This allows for cross-metaphorical connections to be established, and potentially new conceptual hybrids to be generated from these cross-connections. Thus new metaphors can define new concepts that have real cultural currency. And as they are entrenched in usage, perhaps in time becoming dead metaphors, this starts anew the ebb and flow of novel concept formation based on established materials. In brief, it appears there is an irreducible threefold interaction between image schemas, embodied mechanisms like metaphor (as well as a host of other mechanisms that cognitive linguistics explores), and background cultural/philosophical assumptions.

How does all this bear on Chinese philosophy? As it pertains to one of the central ideas in Chinese thought, xin, there are a host of linguistic metaphors deployed in various contexts that aim at human cultivation. Embodied structures like metaphor enact worldviews often by way of linguistic vehicles. The resources from cognitive linguistics further allow for an examination of metaphoric structures illuminating, beyond their mere linguistic form, how we conceive, feel, interact, and so forth. This view of metaphor and image schemas I think strongly resonates with Chinese philosophy; it will also be used to disclose how radically different certain Daoist notions are when compared with some deeply entrenched assumptions in western philosophy. ${ }^{4}$

\footnotetext{
${ }^{4}$ For similar explorations, see Slingerland 2003, 2004, and 2011; and Chong 2006. Edward Slingerland (2011), for example, argues that research in cognitive science indicates that metaphoric thinking is more fundamental and widespread than previously thought, challenging a standard view that western ways of thinking are "analytical" (not metaphor-based) and fundamentally different from eastern ways of figurative and metaphorical thinking. While I am generally sympathetic to Slingerland's claims, firstly it ought to be kept in mind that cognitive linguistics is one research program among other (at times competing) research programs. And secondly, in spite of my general agreement with Slingerland, I shall argue for a middle ground: while eastern ways of thinking are more attuned to the omnipresence of metaphoric thought, incommensurabilities between worldviews emerge via the (differential) threefold interaction of image schemas, metaphors, and background philosophical assumptions.
} 


\section{LIGHT METAPHORS AND XIN}

A central image schema operating tacitly across philosophical traditions is the CONTAINER schema. Aristotle, for example, uses container metaphors for conceptualizing place as well as for classifying statements regarding predications that can be made of a subject. ${ }^{5}$ The Aristotelian use of container metaphors is informed by specific metaphysical aims and background projects (for instance, providing an epistemically satisfactory account of the nature of things). However, as alluded to above, it is important to distinguish the linguistic use of such metaphors from the embodied, nonpropositional CONTAINER image schema. This becomes especially apparent regarding its employment in Chinese philosophy and the metaphors associated with xin that Ning Yu (1998, 2009) extensively maps from a cognitive linguistics perspective. In this section I briefly cover a few of Yu's ideas, and also some of Edward Slingerland's similar analysis, as they relate to xin and light metaphors occurring in Chinese philosophy, specifically those that have associations with Daoism.

One metaphor that $\mathrm{Yu}$ analyzes which links xin and light is the HEART AS LIGHT SOURCE metaphor: "The changes of the light source will change the visual perception of the things in the light of this light source" (Yu 2009, 55). What is interesting is the bridging role that "spiritual light' (shen-ming)" plays in relating xin to nature: such light "refers to the totality of the spiritual and mental aspects of a person...[; it accounts for] the unity and correspondence between nature and man" (Yu 2009, 56). In other words, xin stands for the totality of a person's being, which if properly channeled expresses harmonization between person and nature. The scope and degree of clarity of one's field of awareness indicates the degree of harmony achieved; thus an "unenlightened" heart's field of awareness is dull and narrow, lacking proper channeling, whereas a sage's awareness shines with wide clarity. ${ }^{6}$

An association of the HEART AS LIGHT SOURCE metaphor further relating xin to nature is that the heart is like water, which can "reflect things only when it is still and

\footnotetext{
${ }^{5}$ In section eight I discuss some of the ways in which, despite shared image schemas, Aristotelian ideas diverge from eastern ways of conceptualizing relationality.

${ }^{6}$ It should be noted that the HEART AS LIGHT SOURCE metaphor is especially prominent in Xun Zi's writings; as a result one might inquire about the extent to which this metaphor is Daoist. Indeed, Erin Cline, in her piece on mirror metaphors, notes that

Xunzi seems to be more concerned with emphasizing clarity than Zhuangzi, who focuses more heavily on stillness. For Zhuangzi and the early Daoists more generally, getting in touch with one's spontaneous, pre-reflective intuitions means settling down and being at ease in the world. Zhuangzi's goal, then, is to make the heart-mind still. For Xunzi, settling down in the Zhuangzian sense could only perpetuate the unrefined state into which we are born. Xunzi thinks we need to work hard at being attentive in order to refine ourselves. The work that it takes to hold a pan of water perfectly straight without even the slightest tilt is another metaphor for his rigorous program of self-cultivation. Xunzi's goal is to make the mind clear so that it is ready to learn (Cline 2008, 342).

As I shall suggest in this section, I think there is a way to finesse these issues by viewing matters from the standpoint of an irreducible threefold interaction between image schemas, metaphor, and philosophical/cultural assumptions.
} 
clear" (Yu 2009, 60). Here the link to Daoism is salient since an "emptying" of xin allows for the reflection of things as they truly are, signifying one's degree of awareness. Somewhat paradoxically, it is the occluding of ego that then allows for the illumination of various foci of one's ever widening field of awareness. But what exactly is being emptied? Concentrating on the linguistic features of metaphor can obscure the deeply embodied preconceptual CONTAINER schema at work, an image schema that enables and affectively charges the very worldviews being configured by the HEART AS LIGHT SOURCE metaphor. ${ }^{7}$ It is important to keep in mind that schemas like these tacitly operate in the background, making possible the relevant linguistic figures and poetic gestures. To clarify how the CONTAINER schema meshes with the HEART AS LIGHT SOURCE metaphor, I shall briefly discuss some insightful objections to Slingerland's similar analysis.

Also applying tools from cognitive linguistics, Slingerland likewise maps a schematic metaphor at work in Zhuang Zi's writings, the SELF AS CONTAINER metaphor, which is linked to (linguistic) mirror metaphors that together express the notion of emptying-out and stillness. Arguing against Slingerland, Erin Cline claims that one

problem with this analysis is that the idea of a mirror being empty (free of defilements) and the idea of a container being empty (having nothing in it) are significantly different, making the supposed connection between the mirror metaphor and the "self as container" metaphor schema appear to be rather thin (Cline 2008, 350).

She also claims that there are two differing metaphor schemes at work in Zhuang Zi's and Xun Zi's uses of mirror metaphors. For apparently Xun Zi places emphasis on the HEART AS LIGHT SOURCE metaphor scheme (as linked to mirror metaphors) and not the SELF AS CONTAINER metaphor. However I suggest that these important objections might actually be conscripted to strengthen Slingerland's approach. Using Lakoff and Johnson's ideas, one could argue that assuming Zhuang $\mathrm{Zi}$ and $\mathrm{Xun} \mathrm{Zi}$ are in fact employing the same general "blended" metaphor scheme, they could be drawing attention to differing "metaphorical entailments" due to differing assumptions that together generate their respective differing worldviews. ${ }^{8}$

More precisely, this blend and its entailments are configured by the (irreducible) threefold interaction of image schemas, metaphors, and background philosophical /cultural assumptions. Recall that an image schema is a recurrent pattern of ongoing

\footnotetext{
${ }^{7}$ Although similar metaphors are employed in Confucianism and Buddhism, a key difference is in the way Daoism emphasizes emptying-out, gesturing back towards our preconceptual, embodied modes of being-in-the-world. For example, Hans-Georg Moeller argues that "Confucians take enormous efforts to cultivate their emotions... [whereas the] Daoists try to eliminate [empty-out] emotions from the heart of the sage" (Moeller 2004, p.119). And for Buddhism in general there seems to be a greater emphasis on "mind and its "spirituality" (Moeller 2004, 150) in comparison to Daoism's emphasis on the body.

${ }^{8}$ Cline argues that Slingerland's analysis only captures certain aspects of metaphoric meaning, and that what matters more are the cultural/philosophical contexts in which the metaphors occur (Cline 2008, 352). Note that this is not a problem from the standpoint of the threefold interaction, which accommodates Cline's (as well as Slingerland's) insights.
} 
ordering activities that dynamically enables and supports various other structures. Firstly, the preconceptual CONTAINER schema (arising from embodied processes such as using a cup or being a physically bounded organism with "inner stuff") enables and supports the HEART AS CONTAINER metaphor, which in turn enables the ideas that the heart can be emptied and that the Way (Dao) can subsequently enter. Secondly, Yu, who offers a more detailed analysis than Slingerland, argues that the HEART AS CONTAINER metaphor (or equivalently Slingerland's SELF AS CONTAINER metaphor) is blended with the HEART AS (LIGHT) SOURCE metaphor. Yu observes that as "a container, the heart has 'precious treasures' stored or hidden in it... [which] are gleaming and glittering (i.e. 'enlightening') as well” (Yu 2009, 323). The container metaphor affords a dispositional view of one's true nature. That is, the treasures stored are actually dispositions-"contained" potentialities - to act in certain spontaneous yet appropriate ways (compare Slingerland 2004 on the various $w u$ forms). The blend with the HEART AS (LIGHT) SOURCE metaphor in turn affords the notion that a sage's heart allows for light to be shed on things, in clear and tranquil fashion. ${ }^{9}$ Thus these metaphors are not merely linguistic devices for conveying the Daoist capacity to "see without seeing," as it were; their visual-affective associations also engage the perceptual-sensorimotor aspect of image schemas, and most importantly engage the wider embodied phenomenological sensibility that one's awareness is clear, emptied, and profoundly attuned.

This view of blending, situated by the threefold interaction, addresses Cline's objections to Slingerland's "thin" analysis of metaphor for Zhuang Zi and Xun Zi. For this view accommodates both Zhuang Zi's insight that xin should be still, and Xun Zi's insight that xin should be clear. The philosophical emphasis on emptyingout for Zhuang $\mathrm{Zi}$ affectively expresses stillness (gesturing beyond the "prison-house" of language, as it were); and the emphasis on clarity for Xun $\mathrm{Zi}$ gestures towards the Confucian dimension of cultivation. Thus Zhuang $\mathrm{Zi}$ and Xun $\mathrm{Zi}$ harness the above blend in differing ways: their metaphorical entailments differ in tandem with their differing philosophical worldviews. ${ }^{10}$ Importantly, though, what both worldviews have in common is that they gesture to the overflowing phenomenological dimensions of skillful "knowing-how" that, like with Johnson's earlier quoted example concerning standing upright, are nonpropositional and image-schematic, although in qualitatively profound ways.

In general, if Chinese modes of thinking are more affective, co-relational, and metaphorical in comparison to western modes of thinking, it would be a reasonable hypothesis that Chinese philosophy is more attuned to our embodied modes of beingin-the-world in no small part because these visual-affective and phenomenological

\footnotetext{
${ }^{9}$ For examples of emptying xin see Zhuang-Zi chapter 2 (Graham 1981, 87) and chapter 7 (98); and for xin as a light source see chapter 5 (77-8), chapter 7 (98), and chapter 13 (259).

${ }^{10}$ In terms of the threefold interaction, we can interpret Cline as placing emphasis on the cultural /philosophical dimension, and Slingerland as placing emphasis on image schemas and metaphor (that together generate worldviews). As an aside, I think Harold Oshima (1983) can be interpreted as arguing for a middle ground between Cline and Slingerland which is compatible with the threefold interaction.
} 
associations are brought forth by the very manner in which Chinese philosophy is done, specifically its attunement to the use of metaphor and poetic language. It is generally acknowledged that poetic language is a well-suited vehicle for gesturing towards embodied preconceptual experience, as well as for disclosing other sorts of embodied experience (conceptual, lived, or otherwise). Furthermore, western employments of similar visual metaphors, emphasizing, for example, the "light of reason," do not draw attention to the emptiness of such attunement. Thus while western metaphors may highlight the illuminating features of reason, in Chinese philosophy the heart is the sun (underwritten by the HEART AS LIGHT SOURCE metaphor), expressing not only a coincident concern with clarity of seeing, but more profoundly an affective harmonization between microcosm and macrocosm. ${ }^{11}$ The "empty" nature of light in particular enables a link between xin and the cosmos for Daoist strains of Chinese philosophy.

In sum, the blend of the HEART AS CONTAINER metaphor with the HEART AS SOURCE OF LIGHT metaphor together with image schemas and background philosophical assumptions engender a significant portion of Chinese (mainly Daoist) worldviews. In particular, background Daoist and Chinese assumptions concerning the various $w u$-forms and the harmonic interrelations between microcosm and macrocosm channel metaphorical entailments whose "surface grammar" in texts gestures to figurative and phenomenological forms of profound experience. As will be discussed later, while there is a similar notion of harmony in Stoicism, Stoicism does not require any "emptying-out" to achieve harmony.

\section{A FRAMEWORK FOR AFFECTIVE PROCESSES PART 1: THE DIMENSIONAL APPROACH}

This section adopts a metaview of the previous material and starts to present a conceptual framework for accommodating the threefold interaction of image schemas, metaphors, and background Chinese assumptions. There are, to be sure, differing interpretive approaches to Chinese philosophy; however I shall try to bracket such issues and focus instead on presenting a model of affective processes that coheres with this threefold interaction. I hope to show that the framework sheds new light on Chinese and Stoic views of self-cultivation. The motivation for presenting the framework is simple: Chinese philosophy is often characterized as thoroughly affective in contrast to western ways of philosophizing; while this is generally accurate, it appears that no metalevel account of affectivity is offered as to

\footnotetext{
${ }^{11}$ Note that the metaphoric expression "the heart is the sun" would be an instance of what Lakoff and Johnson call a (higher-order) "conceptual" metaphor, a metaphor enabled by image schemas and blends with (what they call) "basic" metaphors (Slingerland's notion of metaphor schemes appear to be higher-order conceptual metaphors under which fall a number of subsidiary metaphors, whether as cognitive structures or in linguistic textual form). See Yu (2009) for details concerning how this mapping works. Note further that while Chinese clarity (ming) is constituted by an affective harmonization, the clarity of (western views of) reason's light tends to issue from reason's disciplined separation from certain emotions. These themes are discussed later in the paper.
} 
why and how differing conceptions of affects enable these differing worldviews. For surely, from a cross-cultural perspective, although there are congruencies, there seem to be significantly differing conceptions of what affects are and what roles they play. Using the language of the previous sections, while there may be universally employed image schemas (and certain other structures that are part of Lakoff and Johnson's research program), it seems the differential interactions of schemas, metaphors, and background philosophical assumptions induce significantly different worldviews. ${ }^{12}$ With this in mind, I present a framework that forms the third pole of a "triadic" comparative engagement with Chinese and Stoic views of self-cultivation.

There is a research program studying affects that mixes a social constructivist approach with what is called a "dimensional approach" (a mixture that I shall refer to simply as "constructivism"). Here and in the next few sections I outline this research program, indicating along the way its relevance to the previous material. In this section I concentrate on how the dimensional approach meshes with the social constructivist approach. The name essentially conveys how affects are modeled: there are dimensional axes representing the major parameters for classifying affective phenomena (for example, a positive-negative valence axis and an orthogonal intensity axis forming a two-dimensional space; affective processes are interpreted as varying continuously along these axes). While dimensional approaches employ differing numbers and types of axes, broadly speaking affective phenomena can be general (for example, moods, dispositions) or specific (anger, joy); can involve an object (the object of one's concern) or not (a diffuse sense of well-being); and can be expressed as "bipolar pairs (happy-sad)" or not "(tension, outrage, terror, and agitation all seem without an exact opposite, or perhaps to share the same opposite of calmness)" (Russell and Lemay 2000, 495). These affective phenomena are framed by eight characteristics, five of which I quickly cover since they bear on constructivism and a comparative view of affects. ${ }^{13}$

A first characteristic is that affect language exhibits fuzzy boundaries, which may issue from cultural language games whose terms, from a cross-cultural perspective, seem comparable and yet cannot be accommodated in a single scheme. For example, $\mathrm{Yu}$ (2009) discusses some key differences between xin and western conceptions of the relations between heart and mind. Fuzziness may also issue from terms that are linked together within one form of life by family resemblance relations, which would preclude precise boundaries for a family of affect-terms, as is nicely illustrated by the rich, overlapping semantic fields paronomastically associated with xin. Closely related is a second characteristic, typicality: prototypical examples anchor the graded

\footnotetext{
${ }^{12}$ Slingerland's 2008 work explores consilient relations between the humanities and the sciences, discussing in much greater detail the issue of shared, species-specific features of cognition and their bearing on the humanities. The sensibility of my essay follows in this spirit, although it explores the ways in which differences can arise via shared resources.

${ }^{13}$ Note that the eight characteristics cohere with Lakoff and Johnson's research program.
} 
extensions of a category. ${ }^{14}$ For example, relative to Chinese philosophy, the prototypical heart-is-the-locus-of-the-mind idea is the basis for blending the HEART AS CONTAINER metaphor with the HEART AS SOURCE OF LIGHT metaphor (as well as a host of associated metaphorical entailments).

A third characteristic holds that for a range of terms, the terms be oriented with bipolar parameters; for example, parameters like positive-negative valence would be general enough to include particular bipolarities like happy-sad. Even for terms not easily given a bipolar representation (such as tension, outrage, terror, and agitation, as mentioned above), the task is still to examine the extent to which these terms have an opposite term (such as calmness). Parameters like intensity aim to capture this diffuse type of bipolarity (tension has high intensity, whereas calmness has low intensity). With respect to Chinese philosophy the bipolar parameters would be non-dualistically conceived, in accordance with yin-yang, and would express the dynamic nature of situated, qualitative achievements.

Two other characteristics that make clear the dimensional approach's tie to social construction are scripts and the relativity of categories. Briefly, a script is a mechanism through which an affective process acquires its cultural gilding, as it were. ${ }^{15}$ Such gilding, in turn, reveals the relativity of categories, as affect categories differ relative to historical periods, socio-cultural factors, etc. It is thus important not to reify the particular dimensional representation being employed, as one must be sensitive to a semantic field's configuration of terms that are embedded in a particular social matrix.

These characteristics of the dimensional approach are used to argue for the view that affects are socially constructed. Briefly, affects are viewed as constructed via what are called "appraisals" (or affect-appraisals) which utilize mechanisms like image schemas, metaphor, scripts, and so forth to generate affective phenomena cohering with the above characteristics and the resources offered by Lakoff and Johnson. In plain terms, an individual processes information in some context using such mechanisms, giving rise to an overall "appraisal" of a situation, such as anger as an affective judgment of a perceived insult.

The upshot is that on constructivism's research program, significant differences are revealed when cross-culturally comparing affective notions. For example, as $\mathrm{Yu}$ writes, the noted constructivist Anna Wierzbicka 'points out [that] the 'heart' is seen in English as 'the organ of emotions' [and] is 'perceived as more closely related to the body than either soul or mind"'. Yu goes on to observe that from a western perspective the heart "is not viewed as a seat of all emotions, but only of emotions that are seen as either 'good' or 'bad'" (Yu 2009, 352). In this regard, western frameworks generally view affect-appraisals as judgments of "good" or "bad" things, such as responses to pleasure or pain (parameters that are modeled via the

\footnotetext{
${ }^{14}$ The typicality of a category draws from work in cognitive linguistics on prototypes and image schemas (recall also the earlier remarks about concept formation occurring on a continuum between subcategorization and metaphor).

${ }^{15}$ More formally, a script is a "prototypical sequence of causally connected and temporally ordered events" (Russell and Lemay 2000, 496).
} 
dimensional aspect of constructivism). ${ }^{16}$ The image schemas, metaphors, scripts, etc. that channel these appraisals rely on a socially constructed framework operating in the background. For in English, while we can say "'his heart was full of joy, bitterness, or sadness," it is awkward to say "'his heart was full of surprise, amazement, or interest"' (Yu 2009, 352). Affective states associated with xin can accommodate the latter sorts of appraisals, given the nondual nature of heart-andmind, but on western models - even interactionist models ("feeling and thinking work together") - there are latent dualities that reveal themselves in what can and cannot readily be said. ${ }^{17}$

From a western viewpoint it makes very little sense to say, for instance, that "anger injures the liver" or "joy injures the heart," since both of these are intertwined with background cultural/philosophical assumptions about the nature of $q i$ and how it is metaphorically conceptualized: $q i$ "goes 'up' in anger, [is] 'slow' in joy, 'deflated' in sorrow, [etc.]" (Yu 2009, 128). While in general western "emotions," a westernized term, no less, are evaluated as good or bad in accordance with the embodied metaphors GOOD IS UP and BAD IS DOWN (recall the earlier discussion of orientational metaphors; see also Kövecses 2000), the socially constructed metaphor system operating here is contextualized by different assumptions concerning the nature of qi: anger is up, but is not thereby classified as "good," while its opposite, fear, is indeed "bad," but not because "bad is down". In other words, if we were to assume the same western metaphor system operating in Chinese philosophy, if sorrow were "bad," joy would thereby be "good" (both of which accord with western usage); but actually here joy is "slow". One reason for this difference is that the heart is not conceived as the seat of certain "emotions" (a westernized term, to reiterate) that are evaluable as good or bad. Instead, as I discuss below, xin appears to harness an image schema that undergirds a range of metaphors in Chinese philosophy, the (preconceptual) EQUILIBRIUM schema. I postulate it is the interleaving of this schema with various $q i$ metaphors that gives rise to a network of associations like those above, which make little sense on western models. This leads us to the following section further considering constructivism and the light it sheds on contrasting models of self-cultivation.

\section{A FRAMEWORK FOR AFFECTIVE PROCESSES PART 2: CONSTRUCTIVISM AND DYNAMIC NOMINALISM}

Constructivism places emphasis on the dynamic interaction of cultural forces and individual affect-appraisals; even stronger, cultural forces are viewed as social constructs that are inextricably intertwined with individual appraisals, making these constructs "transactionally real" entities - a view cohering with our (irreducible)

\footnotetext{
${ }^{16}$ For a neo-Stoic view of affects as appraisal-judgments, see Nussbaum 2001.

${ }^{17} \mathrm{Yu}(1998,2009)$ presents ample evidence of this, especially with respect to the integral relations between the five-element schematism in Daoism, the unity of micro and macrocosm, and the concepts associated with Chinese medicine.
} 
threefold interaction. ${ }^{18}$ Social constructs are also viewed as higher-order entities, but with two qualifications. First, they are parasitic on individual appraisals, so they are not self-standing entities. Second, constructivists still want to acknowledge that such higher-order entities are not just a collection of individual appraisals; they are in some sense genuinely "real".

Paul Griffiths, borrowing from Ian Hacking's work (1995) on multiple personality syndrome, offers a plausible way to interpret the claims that affective social constructs are not self-standing and yet are more than just a collection of individual appraisals. He notes that things like "citizens, members of parliament, and licensed dog owners are social constructions while electrons, magnesium, and clades are not. The categories referred to in the first list are social constructions, whereas those referred to in the second list are not" (Griffiths 1997, 145). What makes each former category more than merely a collection of individuals is the idea of "dynamic nominalism," which "differs from simple nominalism in that the members of a category do share something over and above the fact that they are members of that category. However, the fact that the members have these shared properties reflects the existence [emphasis mine] of the category and the social practices in which it is embedded" (Griffiths 1997, 146). These practices are ways of being that reflect the commitments of practitioners. The "dynamic" element has to do with the genuine difference practice makes for its members. As applied to affects, socialized affects express categories that are constructed; the categories exist since they are parasitic on individual appraisals that in turn have shared properties by virtue of their shared practices. Yet constructed affects are not merely the enumeration of individuals-withappraisals (and so are not merely nominalistic); the characteristic that makes these constructs "real" is the dynamic aspect of adopting what they afford within a practice: they enact forms of life that make genuine differences for its practitioners and how they practice. As this pertains to Chinese philosophy, xin and its surrounding background assumptions, the five-element schematism in Daoism, etc., express categories that exist in that they enact ways of being that have genuine effects, in the practice of Chinese medicine, for instance.

From our metalevel perspective, dynamic nominalism can be interpreted as a tool bringing into relief emergent features stemming from the threefold interaction of image schemas, metaphors, and Chinese assumptions. In particular, given that xin is a core Chinese idea indicating the thoroughly integrated nature of "affective cognition" (compare Chong 2011), from this metalevel perspective xin is a socially constructed category, an instance of dynamic nominalism, whose network of associations (underwritten by the threefold interaction) affords and generates an overall "cadence" distinctive to Chinese philosophy. One core idea in this network is the notion of harmony (he). There is a similar notion in Stoicism (homologia), but it

\footnotetext{
${ }^{18}$ I should further point out that I am appropriating particular sort of weak social constructivism because of its coherence with the threefold interaction. That is, weak social constructivists generally hold that there are at least three intertwined levels for understanding social affects: the biological level (which accommodates insights coming from evolutionary psychology), the psychological level (which accommodates work coming from cognitive linguistics), and the cultural/social level.
} 
is configured quite differently. I hypothesize that one important thing they both implicitly employ is the preconceptual BALANCE image schema that is fed into differing metaphoric and cultural systems, which then envision-and-enact harmony in quite distinct ways.

According to Johnson, the BALANCE schema arises from "acts of balancing and through our experience of systemic processes and states within our bodies" (Johnson 1987, 75). This image schema consists of a proportional "arrangement of forces around a point or axis" (Johnson 1987, 85), and is based on bodily experiences like maintaining an upright stance. The BALANCE schema is discernable in various metaphors in Daoist writings, which draw forth the aim of establishing a harmonious balance amidst transformation (e.g., chapters 16 and 55 in the Dao-De-Jing; chapters 3, 12, and 13 in the Zhuang-Zi). Furthermore, it appears that higher-order metaphors appealing to harmony and balance, metaphors harnessing the preconceptual BALANCE schema, actually gesture "back" to the preconceptual, embodied roots of this very schema. Yu $(1998,2009)$ maps a number of the metaphors and image schemas at play in conveying this dynamic sense of harmonic-balance. For example, one metaphor that $\mathrm{Yu}$ discusses is the CHANGES ARE MOVEMENTS metaphor, which is structured by the BALANCE schema (in addition to a series of other important image schemas). However the BALANCE schema by itself does not appear to be rich enough to support the diverse uses of higher-order metaphors present in Chinese philosophy. It seems an enriched schema, the preconceptual EQUILIBRIUM schema (which stems from the prototypical BALANCE schema), is being harnessed, as it better coheres with a Chinese sense of multimodal harmonic-balance.

According to Johnson, the EQUILIBRIUM schema builds on the prototypical BALANCE schema, and "results from the continuous mapping of symmetrical force vectors meeting at a point onto a curved surface" (Johnson 1987, 86). In other words, whereas the prototypical BALANCE schema is conceived of "one-dimensionally," with two forces counterbalancing along this dimension, the similarly preconceptual but richer EQUILIBRIUM schema accommodates multiple dimensions that dynamically and continually establish a "thicker" homeostatic balance. ${ }^{19}$ Such a multi-dimensional balance I think offers a more natural fit with Daoism's various $w u$-forms and their characterization as potent, overflowing forms of emptiness that gesture towards maximally skillful achievements effortlessly balancing a host of considerations.

By contrast, Stoic views of harmony-for example, of calming the mind to reveal one's place in nature, encapsulated in the notion of amor fati-seem to primarily harness the BALANCE schema and not so much the EQUILIBIUM schema. To bring this

\footnotetext{
${ }^{19}$ Observe that jing, which can be rendered as "equilibrium," is foregrounded by yin-yang; that is, (high-level, linguistic) metaphors relating to jing are situated by a wider background context (see, for example, chapters 16 and 26 in the Dao-De-Jing). Given the high-level employments of jing, it still appears plausible that the preconceptual EQUILIBIUM schema is being harnessed by various Chinese metaphors. It should also be noted that a Daoist dynamic equilibrium (obtained via an emptying-out) is an achievement gesturing back towards a preconceptual, embodied sense of (cosmic) experience. So even if the preconceptual EQUILIBIUM schema is being harnessed, that isn't equivalent to the achieved state of "sagely jing".
} 
into view, the next section sketches Stoic views of affects, which carry a residual duality that I think issues from a unique interaction of image schemas, metaphors, and background assumptions. My working hypothesis is that from the differential interactions of these three things emerge quite different overall philosophical sensibilities concerning self-cultivation and harmony, even if Stoicism and Chinese philosophy harness similar basic resources like the BALANCE schema.

\section{STOIC VIEWS OF AFFECTS}

It is important to keep in mind that as with Daoism (and much of Chinese philosophy), Stoicism views philosophy as a way of life, a stark contrast to the tenor of modern western philosophy since Descartes. To the extent that any western philosophical tradition aims at bridging the gap between theory and practice, Stoicism is a prime candidate. Building on the previous sections, I think that what is at work are two differing socially constructed views of affects and the roles they play in selfcultivation. Comparing the two worldviews reveals not just two similar yet quite different ways of life, but also assumptions running through these worldviews that appear to be philosophical at root.

While Stoics are a diverse group, there are several common themes. One prominent feature is the privileging of reason as the key regulator of one's dispositions. Stoics also emphasize reason's place in nature and the smallness of our lives in relation to the cosmos. It is presupposed that the cosmos expresses a rational order within which all things have a function. To discern our function is to discern how we accord with this cosmic order, which requires appropriate judgment that then allows things to "shine" forth in the light of reason, in particular, the harmony (homologia) between one's inner rational dispositions and the larger cosmic rational

order. ${ }^{20}$ Stoic harmonization shows certain similarities to Chinese harmony $(h e)$ and its relations to Daoist notions of letting-be. However such shining doesn't stem from any emptying-out; instead there seems to be present a reason-as-light-source metaphor.

For example, Marcus Aurelius utilizes light metaphors in conveying how one ought to cultivate judgment: "The soul as a sphere in equilibrium: Not grasping at things beyond it or retreating inward. Not fragmenting outward, not sinking back on itself, but ablaze with light and looking at the truth, without and within" (Aurelius 1989, 11.2). While this may appear like it harnesses the (preconceptual) EQUILIBRIUM schema alluded to previously, it better fits with the implicit use of the BALANCE schema, as it emphasizes a one-dimensional balancing of competing forces to bring forth the "light of reason". The dual poles of the balancing relation require cultivating one's judgment to properly grasp matters that are neither "beyond" nor merely "inward". Such judging also manifests a finely tuned attentiveness (prosoche) that is neither "fleeing [on the one hand, nor]...pursuing [on the other]" (Aurelius 1989,

\footnotetext{
${ }^{20}$ See for example Long and Sedley (1987), section 63.
} 
11.11). In general, Stoic metaphors tend to emphasize these sorts of dyads between inner and outer, between micro-dispositions and a macro-cosmos.

Furthermore, attaining proper Stoic judgment issues in a "blazing" light of reason that is neither disembodied nor non-"emotional". Stoic reason is affectively conceived, but it is situated by a latent (non-Cartesian) duality not present in Chinese uses of light metaphors and the roles of xin. Stoics make a distinction between pathological affects (pathe) and "good" or non-pathological affects (apatheiai). Blocking the bad affects and cultivating the latter bring forth the light of reason, which displays the above sort of "balance". ${ }^{21}$ Furthermore, balance, light, and reason are intimately related to learning to love one's fate in the cosmic order of things. As Pierre Hadot writes:

The Stoic's fundamental attitude is the love of those realities in whose presence he is constantly placed by the [cosmos], which are intimately linked to him, and with which he somehow identifies himself: Harmonize yourself with the things to which you are linked by Destiny. For the basis of reality is love...natural processes are, in the last analysis, processes of union and of love (Hadot 1998, 230-1).

Amor fati is not flatly the love of fate; it is the Stoic expression of harmonizing/balancing one's dispositions with the rational cosmos, the achieving of proper judgment via the cultivation of one's apathetic affective processes. Learning to (apathetically) love fate liberates one from the "grasping self," as it were, thus revealing one's true shining self and its transitory place within the cosmos.

These notions appear broadly compatible with Chinese harmony. Interestingly, Hadot draws a number of parallels between Stoicism and Chinese philosophy (Hadot 1989, 310-11): the development of metaphysical concerns that are geared toward moral cultivation; the mutual concern with harmonizing one's micro-dispositions with the macro-cosmos; and the parallel recognition of our smallness of place in nature that is actually part of learning to maximize one's being. In spite of a range of affinities, one crucial difference is that for the Stoics there doesn't seem to be a harnessing of the EQUILIBRIUM schema, specifically, of its multimodal affordances that Daoism appears to channel. For there is still a latent duality present in Stoic views stemming from how affects are characterized, where finding balance requires

\footnotetext{
${ }^{21}$ One under the control of pathological affects is viewed as unbalanced, in contrast to a Stoic sage whose "arrow" of reason (the light shining on things) is held in proper "tension" (Long and Sedley 1987, 422). Such tension is a balance whose strength issues from following the consistent (harmonizing) direction that reason indicates. Aurelius similarly writes:

The sun appears to be poured...in every direction but not poured out. For this pouring is extension, and so its beams are called rays from their being extended. ...The pouring and diffusion of the understanding then should be similar, in no way a pouring out, but an extension, and it should not rest forcibly or violently on obstacles that meet it nor yet fall down, but stand still and illuminate the object that receives it; for that which does not reflect it will rob itself of the light (8.57).
} 
shunting off pathological affects. ${ }^{22}$ One noticeable difference is that whereas Daoist affectivity gestures towards the preconceptual embodied roots of being-in-the-world, Stoics recommend reining in certain affects. Informally, social construction for the latter might be advertised as a humanist regimen for building an "inner citadel," whereas construction for the former actually de-constructs in order to leave us with "spontaneous, effortless play". We end up with two quite different versions of harmony, even if similar sorts of equanimity and "naturalness" emanate from a Stoic sage and a Daoist sage. From a metalevel view, it appears that Stoic and ChineseDaoist systems end up differing in the interaction of image schemas, metaphors, and background assumptions because there is a fundamental difference how they conceive of affects. ${ }^{23}$ The last two sections unfold this claim.

\section{SOCIAL SYNDROMES AND CONSTRUCTIVISM: CONTINUING TO UNCOVER ROOT ASSUMPTIONS}

Differences in Chinese and Stoic worldviews become especially clear regarding how affects are conceived. In contrast to the Stoic split between pathological affects and those that are not, Chinese views of xin emphasize channeling one's dispositions by learning to balance multiple modalities (yin-yang). There is an antagonistic duality present in the former and an embracing of opposites in the latter. To further bring forth the differences that emerge at the level of (triadically) comparing worldviews, I begin by further cashing out constructivism.

Recall that dynamical nominalism views affective constructs as real because they enact ways of being that make genuine differences for its practitioners and how they practice. According to Griffiths's survey of affective research programs, a key idea of constructivism is the classification of certain culturally constructed affects as "syndromes". Firstly, a syndrome is dynamically nominalistic because members of a practice interpret an affect as a "passion" (as that which is suffered), which enacts a mode of behavior interacting with individual appraisals. A good illustration of this general phenomenon is the (widely cited) syndrome of amok, exhibited in certain Southeast Asian societies (see Averill 1982 and Griffiths 1997). Triggered by a

\footnotetext{
${ }^{22}$ Pathological affects need to be blocked off, apparently channeling the force dynamic BLOCKAGE schema (recall the proper "tension" in which a sage holds things; I suspect that the BALANCE schema and BLOCKAGE schema are blended to convey how such proper tension is harmonious). By contrast, for Daoism those affective processes that result in blockage (e.g., the discussions of benevolence, ritual propriety, etc. in Zhuang-Zi) need to be unobstructed. Balance for the former issues from a disciplined separation ("blocking off"), whereas equilibrium for the latter issues from emptying-out ("unblocking") separations.

${ }^{23}$ Note that if we assume there are certain universally shared image schemas (basic metaphors, etc.) as Slingerland $(2008,2011)$ argues, which I tend to agree with, that still leaves unexplored the interaction of schemas, metaphors, and background assumptions. Furthermore, if my working hypothesis - that some of the incommensurabilities between Stoic and Chinese-Daoist worldviews issue in part from the differing ways that these worldviews channel the BALANCE and EQUILIBRIUM schemas, respectivelyis not wholly correct, the framework I offer still presents a plausible outline of how incommensurabilities can emerge even with shared image schemas (etc.).
} 
socially perceived dishonor (for example, a victim of an affair; the inability to provide for family; etc.), a male "runs amok" by attacking others with varying degrees of violence. The behavior is socially interpreted as a disclaimed action (similar to a momentary insanity plea) and others briefly tolerate such violence, but the affair usually ends with group members killing the male. The sense in which running amok is a passion has to do both with the fact that the man is not pretending to be in a frenzy (amok is genuinely suffered by that person), and because it is also interpreted as a disclaimed action by others - amok requires the mutualism of being affected by circumstances and acting in response to being so affected. ${ }^{24}$ Secondly, the sense in which amok is a constructed syndrome has to do with the recognition that the man who runs amok "would not be in a [genuinely suffered] frenzy unless he had learned that this is an appropriate response to certain unbearable social pressures" (Griffiths 1997, 141). The syndrome affords a new mode of behavior since the practitioners tacitly adopt the interpretation; this "meme," as it were, spreads insidiously through a cultural matrix. Thus amok, from a higher-order perspective, is both a form of display (at the group level), and a felt state (at the individual level). It is an enacted mode of activation tapping into two systems, a cultural-level system and an individual appraisal system, jointly required for understanding the dynamical nature of affective syndromes.

The emphasis on tacit interpretation is crucial, since it makes certain socially constructed affects (like amok) "covert" constructions. They are not overt, because if the community of practitioners and the person running amok were to realize that it is merely an interpretation of a passion as a disclaimed action, the practice would diminish in force (or to illustrate with a different example, multiple personality syndrome is a social pretence that cannot survive the realization that it is merely our invention; see Griffiths 1997, 145-146). As Griffiths notes, these covert categories "are ontologically on a par with overt social constructions but are treated by the community as if they corresponded to independent distinctions in nature. They are treated in the same way as categories like chlorine or motor-neuron disease" (Griffiths 1997, 147). What makes covert social constructs powerful and at the same time seemingly paradoxical from a metalevel view is that individuals are appraising a syndrome as a passion, and thus are making "active" (enacted) judgments, yet for the practice to make a difference for that form of life it must be tacitly understood as a disclaimed action.

As applied to Stoic views of affects, their normative prescription to affirm the apathetic affects looks to issue from a concealed separation between cultural-level and individual-level constructs. Firstly, the covert dimension concerns the characterization of pathological affects as out of our control-as disclaimed actions, once they are engaged (anger is the strongest of the pathological affects, and a

\footnotetext{
${ }^{24}$ Such "mutualism" appears to be broadly compatible with Stoic and Chinese views of affects. That is, for Stoics the mutualism regards, on the one hand, being affected by fate, and yet on the other hand choosing to affirm only the apathetic affects; and for Chinese views, on the one hand, being affected by social demands (for example, the demands of ritual propriety), and on the other hand acting with cultivated efficacy.
} 
common target of Stoic writings; see Seneca's De Ira, for example). Furthermore, the division made between pathe and apatheiai is not viewed merely as an interpretation; it is taken for granted within a wider normative, philosophical framework. Stoicism aims to harness and channel human energies, which requires creating technologies of the self (Aurelius's meditative exercises provide an instructive example). One must dwell in what the Stoic framework affords - the split between good and bad affects, learning the acceptance of fate, etc. - to then reap the benefits of this way of life. However, by adopting a metaview on the Stoic framework one can better glean that the pathological affects are characterizable as syndromes (socially constructed categories) whose features play an integral part of the Stoic way of life.

While the pathological affects are viewable as syndromes, this is not true of the good ones, since to do so would not fit with the Stoic "invention" of will (see Inwood 2005). In other words, "will" (voluntas) is what allows for the Stoic's affirmation of good affects, as well as a compatibilist rendering of self-determination juxtaposed with cosmic fate. What this reveals, I think, are predominantly western presuppositions that are philosophical at root; after all, what really justifies the separation between pathological affects and those that are under the domain of willed (non-syndromic) affects? If anything, the "gerrymandering" of affective territory reveals the socially constructed nature of Stoic therapeutics, whose various disciplined separations are part and parcel of Stoic harmonization and self-cultivation.

To recap the important disciplined separations: Stoics first divide affects into two types, claiming one is a disclaimed action while the other can be controlled. This split runs in tandem with the crucial piece of cognitive technology, the invention of will, as a way to render compatible assumptions about cosmic fate with the ability to control crucial elements of one's being. These elements are then brought together in the affirmation of reason and the cultivation of judgment. From our metalevel view, pathe, apatheiai, will, reason, and judgment are instances of dynamically nominalistic social constructions. Furthermore, the constructivist claim that certain cultural affects are syndromes applies only to the Stoic characterization of pathological affects. Together these constructs induce "partitions" of the self, whereupon Stoic therapy offers a means to configure this territory. In brief, what I think is revealed from our metaview is that Stoicism contains socially constructed dualities: fundamental assumptions within its project of self-cultivation that are at the same time unavoidably philosophical, and whose nature is not so easily discerned from within the Stoic framework itself.

\section{COMPARING WORLDVIEWS: PUTTING THE PIECES TOGETHER?}

Mary Tiles and Jinmei Yuan (2004) in similar fashion excavate some of the root differences in western and eastern worldviews. On the western side, there is a widely used tree metaphor (made systematic by Aristotle) that aims at classifications of genera and species - classifications utilizing a series of oppositions concerning what can be said of a thing, which in turn generate the tree's branching structure. The epistemic tree metaphor relies on a philosophical outlook that contains a latent 
dualism concerning the search for dyads that accord with this higher-order metaphor (underwritten it appears by a range of image schemas, basic metaphors, and so forth). By contrast, the multimodal channeling of the EQUILIBRIUM schema in Chinese philosophy accords with co-relational thinking, not merely the employment of dyads geared towards classification. As Tiles and Yuan write: "It is impossible to find a single fixed order by locating terms in a changing world. Instead, to find countless relationships between counterparts [yin-yang] could be an effective way to describe the world" (Tiles and Yuan 2004, 143). Such co-relational thinking might be characterized as a thick dyadic mutualism, paralleling the difference between the onedimensional harnessing of the BALANCE schema and the harnessing of the richer multimodal EQUILIBRIUM schema. In their paper, Tiles and Yuan go on to argue for certain incommensurabilities between these worldviews, although they do not address whether there might also be deeply shared resources that nevertheless play central roles in generating these incommensurabilities. In this final section I speculatively explore the question: what is the nature of the incommensurabilities induced by the interactions between schemas, metaphors, and philosophical assumptions?

With respect to philosophical assumptions, in comparison to Stoic views, on the Chinese model there is no love of fate, as Stoic fate presumes an underlying rational order of things. It also appears more generally that this presumption channels the widespread use of the western tree metaphor and the (epistemic) quest for a complete "tree of knowledge". So here it would seem is a philosophical "seed" fed into a threefold interaction from which incommensurabilities emerge. Daoism by contrast doesn't presume a hidden rational order; rather there is primarily inexhaustible creative flux, a philosophical assumption fed into another threefold interaction that generates a differing worldview. ${ }^{25}$ Such "inexhaustible creativity" draws forth perhaps the central difference between Stoicism and Daoism, as it highlights the reflective, interpenetrating nature of even the interaction itself. This is similar to Dewey's notion of a reflex arc but more radical, as it is misleading to say that the threefold interaction "mirrors" or "reflects" the metaphysical "order" of creative flux. Allow me to clarify.

In Stoicism there are certain bedrock notions that allow for firm reference, for example "Fate" as reason embodied in the cosmos, allowing us to grasp its nature and thus our relation to that nature. Furthermore, the fixed character of pathological affects serves as a bedrock philosophical category motivating the introduction of will and the role of judgment in affirming the apathetic affects, which are crucial ingredients in forming our dispositions, on which the Stoics place so much emphasis. So while Stoicism ends up with notions resonant with Daoism such as harmonization and the importance of "balancing," the paths are quite different due to their overall differing worldviews. The latent dualities present in Stoicism lead to the use of light metaphors that highlight harmonizing one's capacity to reason with a larger rational

\footnotetext{
${ }^{25}$ While Dao is also characterized as constant, it is the interpenetration of being and non-being-Dao's creative originary aspect - that is highlighted here, which also accords with not reifying shi-fei distinctions (see, for example, Zhuang-Zi chapter 2).
} 
order, as well as metaphors that, because of these dualities, present the path of cultivation as a struggle between opposing forces, where choice is required to have any hope of achieving liberation. Light is separated from "dark" (pathological affects, not following reason, and so forth), where achieving cosmic harmonization is set in opposition to these other forces.

For Stoicism and Chinese philosophy, the (differential) threefold interactions of image schemas, metaphors, and background assumptions induce overall philosophical worldviews geared towards self-cultivation. The Stoic technologies of the self-for example, Aurelius' daily meditations; the use of, and training in, Stoic logic; learning to attune one's attention; and so forth - are grounded in these interactions, which while process oriented (aiming as they do at forging proper dispositions) hide dualities that are fundamentally different from Daoist views. For the threefold interaction in Daoist strains of Chinese philosophy tends to erode any duality, embracing the interpenetrating nature of oppositions (e.g., Dao-De-Jing chapters 16, 22, and 42; Zhuang-Zi chapters 12 and 27). What this means for our metalevel discussion is that even the interaction cannot be separated from cosmic, co-relational flux. ${ }^{26}$ Light is thus not cleaved from dark; "will," to the extent that any similar but ultimately incommensurable notion exists (compare Bruya 2010), is not generated by an opposition to pathological affects; judgment is not a faculty; and so forth. More generally, western categories that partition "mind" into things like reason, belief, desire, will, emotion, and so forth are separations incommensurable with Chinese worldviews that do not share the same root assumptions. ${ }^{27}$

Daoism does not attempt to put Humpty-Dumpty back together, as it were, which Stoicism (and the western tradition more generally) does, since there is not any such problem to start with; heart and mind are already integrated from the start. Daoist "technologies" of self-cultivation harness potentialities that in a sense are already there, yet at the same time require appropriate channeling to awaken us to our original naturalness. In sum, the interaction of image schemas, metaphors, and background philosophical (mainly Daoist) assumptions enacts a way of being that redounds (and perhaps "resounds," but not, from a western view, "mirrors") to what this very interaction, this overall worldview, is gesturing towards, namely an inexhaustible cosmic affectivity. This is not an affectivity that re-flects, re-presents, or aims to reintegrate forms of experience within a larger cosmos; for there is no initial split between, say, pathological affects and good ones. Western ways of thinking are inclined to raise questions like: What is an affect (perhaps for epistemic purposes of classification)? What are the relata of an affective relation? What is the contrast class of affects? But such questions themselves reveal western presuppositions about western ways of conceiving. These sorts of questions are not germane in a Daoist

\footnotetext{
${ }^{26}$ Such "self-reflective" interpenetration I think also coheres with Daoist deployments of "goblet words" and paradoxical expressions.

${ }^{27}$ To reemphasize, even though there may be universally employed image schemas (basic metaphors, etc.), differences emerge from the interaction of image schemas, metaphors, and background assumptions. The incommensurabilities between worldviews emerge most prominently in how affects are conceived - one invoking disciplined separations, and the other emptying-out any such separations.
} 
context, as these questions contain the encrustations of modes of thinking that Daoism would aim to dissolve. ${ }^{28}$

One might conjecture that the "emptied" nature of Daoist affectivity is the creative Dao itself, making ineffectual the question "what are Daoist affects?" For such a question conjures a gap between an account of affects and what that account signifies. As Hans-Georg Moeller writes:

Ancient Chinese philosophy in general, and Daoist thought in particular, does not tend to suppose an "ontological" gap between the realms of representation and presence. An ancient Chinese "semiotics of presence" rather conceives of both the signifier and the signified as equally present. ...The Daoist ineffable, the Dao, is...the nonpresent pivot around which everything that is present revolves. It is that central element in the world that is empty of both name and form (Moeller 2004, 145).

Thus it would seem that the question "what are Daoist affects?" is empty in answer and form precisely because Daoism, in emptying out such a question and its presuppositions, is gesturing back to an embodied cosmic presencing, where Daoist affectivity is the very "pivot" alluded to. If this is the case, it only indicates just how radically different these worldviews are. ${ }^{29}$ In other words, the insufficiency of western frameworks, even constructivism, to capture the "bottomless mutuality" of such affectivity is a limit brought forth by the very presuppositions (predominantly western) that enable these ways of seeing. The "light" that these similar yet ultimately incommensurable worldviews shed on self-cultivation is in the end quite different, as the worldviews conceal differences that it appears are unavoidably and inseparably philosophical at root. Finally, if these speculative remarks are on the right track, it would seem that what this paper's triadic approach signifies is neither universality nor difference as such, but rather the emergent features of differences-via-universals, some features of which efface themselves in the process of being brought into view.

\footnotetext{
${ }^{28}$ Thus while (sagely) knowing-how is good, knowing-that is not (Dao-De-Jing chapter 48; Zhuang-Zi chapters 2 and 23 ).

29 The nature of the incommensurabilities also realigns the traditional contrast between (western) analytic modes of proceeding and ("Chinese") holistic modes of being (compare Hansen 2000). I suggest, but shall not argue for the claim, that the incommensurabilities are best viewed as products of semiosis, where a Daoist "semiotics of presence" would differ from, say, a Mohist "semiotics" of analysis because of their differential threefold interactions (whose emergent contrasts would be brought into relief due to these interactive dynamics). Such incommensurabilities can be conceptualized metaphorically as distinct complexes in a semiotic landscape; the truly radical claim would lie in what a Daoist semiotics of presence signifies, as it apparently would empty out even this meta-level metaphoric image. Note that this image also accommodates various commensurabilities ("overlapping complexes") between eastern and western views (as well as within these respective traditions). My selective approach has focused only on certain incommensurate "peaks of interest," as it were, and is certainly not intended to be representative of ancient Chinese philosophy in general.
} 


\section{ACKNOWLEDGEMENTS}

I owe many thanks to several anonymous referees of the journal Comparative Philosophy for their insightful, detailed, and sympathetic yet critical comments, which have greatly contributed to the development of this paper. Any mistakes, of course, remain my own.

\section{REFERENCES}

Aurelius, Marcus, Mediations, trans. A.S.L. Farquharson (1989) (New York: Oxford University Press).

Averill, James (1982), Anger and Aggression: An Essay on Emotion (New York: Springer Verlag).

Bruya, Brian (2010), "The Rehabilitation of Spontaneity: A New Approach in Philosophy of Action", Philosophy East and West 60 (2): 207-250.

Chong, Kim Chong (2006), "Zhuangzi and the Nature of Metaphor", Philosophy East and West 56 (3): 370-391.

Chong, Kim Chong (2011), “Zhuangzi’s Cheng Xin and Its Implications for Virtue and Perspectives", Dao: A Journal of Comparative Philosophy 10: 427-443.

Cline, Erin (2008), "Mirrors, Minds, and Metaphors", Philosophy East and West 58 (3): 337-357.

Cornelius, Randolph (1996), Science of Emotion: Research and Tradition in the Psychology of Emotions (Upper Saddle River, NJ: Prentice Hall).

Damasio, Antonio (1994), Descartes' Error: Emotion, Reason, and the Human Brain (New York: Putnam).

Damasio, Antonio (1999), The Feeling of What Happens: Body and Emotion in the Making of Consciousness (New York: Harcourt).

Damasio, Antonio (2003), Looking for Spinoza: Joy, Sorrow, and the Feeling Brain (New York: Harcourt).

Damasio, Antonio (2011), "The Quest to Understand Consciousness": <http://www.ted.com/talks/antonio_damasio_the_quest_to_understand_conscious ness.html $>$.

Gibbs, Raymond (2005), "The Psychological Status of Image Schemas", in Beate Hampe (ed.) From Perception to Meaning: Image Schemas in Cognitive Linguistics (Berlin: Mouton de Gruyter), 113-136.

Graham, Angus (1981), Chuang-tzu: The Seven Inner Chapters and Other Writings from the Book Chuang-tzu (Boston: Allen and Unwin).

Griffiths, Paul (1997), What Emotions Really Are: The Problem of Psychological Categories (Chicago: University of Chicago Press).

Hacking, Ian (1995), Rewriting the Soul (Princeton: Princeton University Press).

Hadot, Pierre (1998), The Inner Citadel: The Meditations of Marcus Aurelius (Cambridge: Harvard University Press). 
Hampe, Beate (ed.) (2005), From Perception to Meaning: Image Schemas in Cognitive Linguistics (Berlin: Mouton de Gruyter).

Hansen, Chad (2000), A Daoist Theory of Chinese Thought: A Philosophical Interpretation (New York: Oxford University Press).

Inwood, Brad (2005), Reading Seneca (New York: Oxford University Press).

Johnson, Mark (1987), The Body in the Mind: The Bodily Basis of Meaning, Imagination, and Reason (Chicago: University of Chicago Press).

Kövecses, Zoltan (2000), Metaphor and Emotion: Language, Culture, and Body in Human Feeling (Cambridge: Cambridge University Press).

Lakoff, George (1987), Women, Fire, and Dangerous Things: What Categories Reveal about the Mind (Chicago: University of Chicago Press).

Lakoff, George and Mark Johnson (1980), Metaphors We Live By (Chicago: University of Chicago Press).

Lakoff, George and Mark Johnson (1999), Philosophy in the Flesh (New York: Basic Books).

Long, A.A. and Sedley, D.N. (eds) (1987), The Hellenistic Philosophers vol.1 (New York: Cambridge University Press).

Moeller, Hans-Georg (2004), Daoism Explained: From the Dream of the Butterfly to the Fishnet Allegory (Chicago: Open Court).

Nussbaum, Martha (2001), Upheavals of Thought (Cambridge: Cambridge University Press).

Oshima, Harold (1983), "A Metaphorical Analysis of the Concept of Mind in Chuang Tzu”, in Victor Mair (ed.), Experimental Essays on Chuang-tzu (Honolulu: University of Hawai'i Press), 63-84.

Russell, James and Ghyslaine Lemay (2000), "Emotion Concepts", in Lewis and Haviland-Jones (ed.), Handbook of Emotions: Second Edition (New York: The Guilford Press), 491-503.

Slingerland, Edward (2003), Effortless Action: Wu-wei As Conceptual Metaphor and Spiritual Ideal in Early China (New York: Oxford University Press).

---- (2004), "Conceptions of the Self in the Zhuangzi: Conceptual Metaphor Analysis and Comparative Thought", Philosophy East and West 54 (3): 322-342.

----(2008), What Science Offers the Humanities: Integrating Body and Culture (Cambridge: Cambridge University Press).

---- (2011), "Metaphor and Meaning in Early China", Dao: A Journal of Comparative Philosophy 10 (1): 1-30.

Tiles, Mary and Jinmei Yuan (2004), "Could the Aristotelian Square of Opposition Be Translated into Chinese?", Dao: A Journal of Comparative Philosophy 4 (1): 137-149.

Yu, Ning (1998), The Contemporary Theory of Metaphor: A Perspective from Chinese (Philadelphia: John Benjamins).

Yu, Ning (2009), The Chinese HEART in a Cognitive Perspective: Culture, Body, and Language (New York: Mouton de Gruyter). 